\title{
Retrograde jejuno-gastric intussusception following Billroth II gastrectomy with Braun's jejuno-jejunostomy
}

\author{
R Gopal, T P Elamurugan, S S Prasad Das, S Hage, R Muthukumarassamy, \\ V Kate, A Ramesh
}
Department of Surgery and Radiology, Jawaharlal Institute of Postgraduate Medical Education and Research (JIPMER), Puducherry, India

Key words: Intussusception; Billroth II

Gastrectomy; jejuno-jejunostomy

\section{Introduction}

Retrograde jejuno-gastric intussusception is a potentially fatal complication of a Billroth II gastrectomy [1,2]. In all, there are just over 200 cases reported [2]. The condition may present with varied clinical presentations like abdominal pain, vomiting, haematemesis, gastric outlet obstruction, intestinal obstruction, and intestinal gangrene [1,3-6]. To the best of our knowledge, there are no reported cases of haematemesis presenting in a patient with retrograde jejuno- gastric intussusception through a Braun's jejuno-jejunostomy. We present a case that highlights an unusual type of retrograde gangrenous intussusception which occurred across two points of previous anastomosis i.e. jejuno-jejunostomy and gastro-jejunostomy simultaneously.

\section{Case report}

A 40-year-old male who had undergone a Billroth II gastrectomy and Braun's side-to-side jejuno-jejunal anastomosis for gastric outlet obstruction five years previously, presented to our emergency department with haematemesis for one day. He had five episodes of vomiting altered blood. He gave no history of similar affection in the past. The

\section{Correspondence:}

Kate V

Department of Surgery

JIPMER

Puducherry-605006, India

Email: drvikramkate@gmail.com patient was haemodynamically stable and abdominal examination did not show signs of peritonitis. An $8 \times 8$ $\mathrm{cm}$ mass was palpable in his left iliac fossa. There was no hepatosplenomegaly. An upper gastrointestinal endoscopy was attempted but visualization was poor due to the presence of altered blood. An emergency CT scan of the abdomen revealed a retrograde intussusception of the jejunum into the stomach across the gastro- jejunostomy (Figure.1). The patient was stabilized and taken up for emergency laparotomy. Intra operatively, the findings of the CT scan were confirmed. The patient had a gastro-jejunostomy and a diverting Braun's side-to-side jejuno-jejunal anastamosis. The efferent limb of the jejunum distal to the jejuno-jejunal anastomosis was seen telescoping across the jejuno-jejunostomy (Figure 2), into the stomach, through the gastro-jejunostomy. Schematic representation of the normal anatomy and the retrograde intussusception is shown in Figure 3. The intussuscepted segment was gangrenous and there was $500 \mathrm{ml}$ of altered blood in the stomach. The remainder of the bowel, including the intussuscepting segment, appeared viable. The jejuno-jejunal anastomosis was taken down, its contents reduced, and the gangrenous segment of jejunum was resected. The gastrojejunostomy was preserved. Bowel continuity was restored with two jejuno-jejunal anastomoses, one proximal and one distal to the gastro-jejunostomy. A Witzel's type feeding jejunostomy was placed distal to the second anastomotic line in the efferent loop. Postoperative recovery was uneventful. The patient was discharged from hospital after tolerating a normal diet and after removing the feeding jejunostomy. He was asymptomatic at the first and second month follow-up visits. 


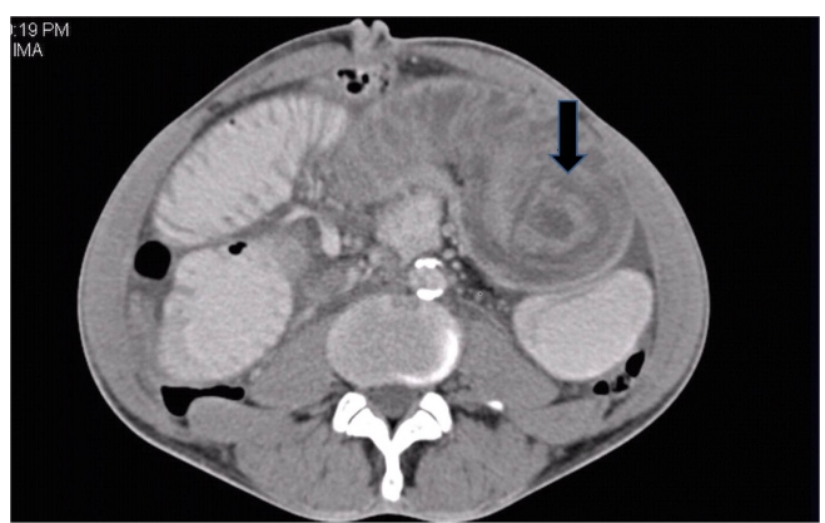

Figure 1: CT scan of the abdomen showing the intussusceptions of jejunum into the stomach via the gastro-jejunostomy.

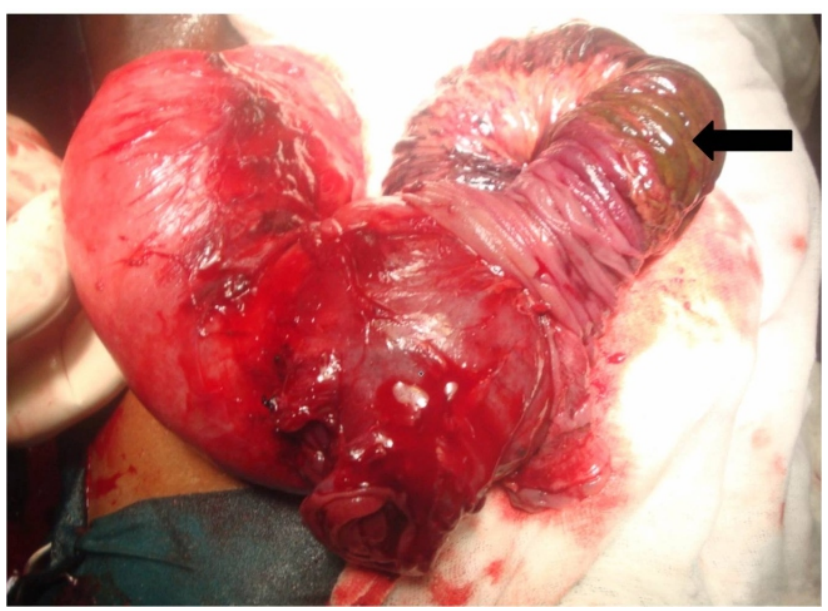

Figure 2: Intra-operative image showing the distal jejunum "telescoping" into the proximal limb across the Braun's jejuno-jejunal anastomosis.

\section{Discussion}

Retrograde jejuno-jejunal and jejuno-gastric intussusceptions are rare, but dangerous long term complications of Billroth II gastrectomy and gastrojejunostomy. Jejuno-gastric intussusception is more common than the jejuno-jejunal variety [7]. There have been reports of retrograde intussusception also in patients who have undergone Roux-en-Y gastrointestinal anastomosis after gastrectomy [8]. However, the occurrence of retrograde intussusception across two anastoamoses has not been reported in the literature. A high index of suspicion and timely investigations like an oesophagogastroscopy or a C.T. scan will help to clinch the diagnosis early. Emergency surgical intervention can help to prevent clinical deterioration and save the life of the patient [2]. All the reported cases of retrograde intussusceptions of jejunum into the stomach through a gastro-jejunostomy have been managed by emergency laparotomy and appropriate resection. In our case too, the relatively early presentation, clinical suspicion and timely imaging helped in the early diagnosis, management and survival of the patient. We emphasize that a high index of clinical suspicion should be maintained in patients with gastro-enteric anastomosis who present with haematemesis, for the possibility of a retrograde jejuno-gastric intussusception.

\section{References}

1. Miah AG, Imam NA, Joarder RH, Talukder SI, Hossain MS. Retrograde jejunogastric intussusception (JGI) with strangulation following previous gastrojejunostomy. Mymensingh Med J. 2006 Jan;15(1):99-101.

2. Tauro LF, Roshan M, Aithala PSM, Hegde BR, Anand IP, John SK. A rare cause of haematemesis: retrograde jejunogastric intussusception. J Assoc Physicians India. 2006 Apr;54:333-335.

3. Edwards JL, Aubrey DA. Retrograde jejunogastric intussusception: report of 2 cases. Br J Surg. 1977 Mar;64(3):177-179.

4. Bapaye M, Kolte S, Pai K, Godse A, Pardeshi A, Bhave A, et al. Jejunogastric intussusception presenting with outlet obstruction. Indian J Gastroenterol. 2003 Feb;22(1):31-32.

5.Gupta S, Singh G. Retrograde jejunogastric intussusception: an unusual cause of hematemesis (a case report). J Postgrad Med. 1986 Apr;32(2):105-106.

6. Wolukau-Wanambwa PP. An uncommon cause of haematemesis--retrograde jejuno-gastric intussusception. Br J Clin Pract. 1979 Feb;33(2):5354,58 .

7.Kwak JM, Kim J, Suh SO. Anterograde jejunojejunal intussusception resulted in acute efferent loop syndrome after subtotal gastrectomy. World J. Gastroenterol. 2010 Jul 21;16(27):3472-3474.

8. Goverman J, Greenwald M, Gellman L, Gadaleta D. Antiperistaltic (retrograde) intussusception after Roux-en-Y gastric bypass. Am Surg. 2004 Jan;70(1):67-70. 